\title{
Mixed-species flocks: an example of niche construction?
}

Nancy M. Harrison* and Michael J. Whitehouse

Animal and Environmental Research Group

Anglia Ruskin University

East Road, Cambridge, CB1 1PT

UK

*Correspondence: nancy.harrison@ anglia.ac.uk 


\section{ABSTRACT}

Mixed-species flocks result from co-evolved relationships between participants: interspecific gregariousness that varies in strength in different species pairs or groups. Such inter-specific associations of birds are a characteristic of most avian communities, observed in diverse habitats from forests to grasslands, estuaries to the open ocean, worldwide in both high latitudes and in the tropics. We explore the consequences of mixed-species flocks in shaping the selective environment and discuss whether the participants in flocks should be identified as niche constructors. As a result of the decision to associate with other species, a bird alters its relationship with competitors; potentially gains access to resources; becomes safer from predators; and may change microhabitat use. The recurrent patterns in the behaviour of disparate unrelated species active in mixed-species flocks have led investigators to conclude that similar selective pressures have shaped their behaviour. However mixed-species flocks are variable in their characteristics, the birds active in them are diverse in form and behaviour, and the selective pressures that have shaped their propensity to join mixed-species flocks must be various. In forming mixed-species flocks, species with specialised roles at the centre of flocks are creating a complex social environment that represents an important biotic selective force shaping their own ecology and behaviour, and that of other species within the avian community. In this review we consider how the spectrum of inter-specific relationships in mixed-species flocks make them an interesting focus for further studies of niche construction by relocation. 


\section{INTRODUCTION}

Inter-specific competition and niche differentiation have been a central focus in ecology and the influence of species upon one another recognised as important in shaping avian communities (Cody 1985; Wiens 1989). Now the evolutionary processes driving niche differentiation are being re-evaluated in a new theoretical context, niche construction, the process by which organisms drive environmental change, modify their relative niches, and as a result become exposed to different selective pressures (Laland et al. 2004; Laland \& Sterelny 2006; Krakauer et al. 2009). Mixed-species flocks of birds, or of birds with other vertebrates, are ubiquitous, observed in diverse habitats from forests to grasslands, estuaries to the open ocean, worldwide in both high latitudes and in the tropics. They are particularly characteristic of forest bird communities, and have been studied extensively at temperate latitudes (e.g. Morse 1970, 1978; Carrascal \& Moreno 1992; Krams 1996) and in the tropics (e.g. Davis 1946; Buskirk 1976; Gradwohl \& Greenberg 1980; Bell 1982; Munn 1985; Hino 1998; Thiollay \& Jullien 1998). Mixedspecies flocks are particularly noted as an important feature of tropical forests, where at times the majority of birds observed are in such flocks rather than apart from them (Latta \& Wunderle 1996; King \& Rappole 2001).

Are mixed-species flocks an example of niche construction? Niche construction is more commonly associated with environmental engineers, creatures such as beavers or ants that modify their physical environment and transform the selective regime for future generations (Odling-Smee et al. 1996; Wright et al. 2002). These species have adaptations that give them an advantage in the habitat of their own construction; their 
offspring have greater success because of a genetic and an ecological inheritance. However, it has been argued (and disputed) that niche construction not only results from environmental engineering ('perturbation'), but also from 'relocation' (Odling-Smee et al. 2003; Laland \& Sterelny 2006). Individuals expose themselves to novel selection pressures as the result of their decisions, for example to occupy a given habitat, in the process influencing selection on other species and driving co-evolutionary episodes (Laland \& Boogert 2008). In forming inter-specific associations, species with specialised roles within mixed-species flocks are creating a complex social environment that represents an important biotic selective force shaping their own ecology and behaviour, and that of other species.

A large literature on mixed-species foraging flocks of birds has been accumulating for more than a century (see Bates 1863 and the comprehensive review by Rand 1954), including elegant detailed behavioural studies (Moynihan 1962; Munn 1985). This represents one category of social aggregation among many (e.g. roosting, migration, breeding), but this particular category - related to the location and capture of food - is peculiar in the recurrence of inter-specific associations and the strength of some alliances. Here we review the literature, considering the evolution of flocking behaviour and the spectrum of co-evolved inter-specific affiliation - from diffusely co-evolved species groups to highly specialised obligate associates. We explore the vocabulary that has been used to describe the roles of species within mixed-species flocks, as these terms reflect the spectrum of inter-dependency and likely trade-offs in the evolution of flocking behaviour. We suggest that mixed-species flocks represent a good system for the study of 
niche construction, and the following review aims to direct attention to areas meriting investigation in this fresh light.

\section{WHAT IS A MIXED-SPECIES FORAGING FLOCK?}

Mixed-species foraging flocks of birds are associations in which participants seek each other out, actively initiating and maintaining their association; the active interactions of a core set of species at the centre of mixed-species flocks differentiate them from feeding aggregations in which birds simply converge on food, water, confined patches of habitat, or a safe roost (Morse 1970). Mixed-species foraging flocks emerge as a result of the co-evolved relationships between participants that vary in strength between different species pairs or groups (Rand 1954; Moynihan 1962). Birds converging on food such as at a fruiting tree may be competing for limited resources, modifying selection, however the inter-specific associations are often ephemeral (Rand 1954) and the impact fleeting.

In practice mixed-species foraging flocks have been defined loosely by the habitat or microhabitat where they occur, the foods taken by participants (e.g. krill, insects), or the species predictably at their centre (e.g. Caldwell 1981; Hoffman et al. 1981; Munn 1985; Remsen 1985; Hunt et al. 1988; King \& Rappole 2001). In forests, criteria for differentiating mixed-species flocks of birds from aggregations may include evidence that participants are moving together - some definitions point to how fast birds are moving and how far apart they are - or calls and signals may provide evidence that birds are affiliated (Wiley 1980; Hutto 1987; Gram 1998; Maldonado-Coelho \& Marini 2003). 
Forest flocks are often conspicuous with incessant calling and signalling (posturing, wing fluttering), thought to be important for initiating and maintaining mixed-species associations (Moynihan 1962; Goodale \& Kotagama 2005a).

The size of mixed-species flocks is extremely variable and not useful in distinguishing them from aggregations. In all examples of mixed-species flocks of passerines there is a small highly interactive core of a few species, which are joined by more, sometimes a great many more, transient participants (Munn 1985). The 'bird waves' of the tropical forests can number 100 or more individuals (Rand 1954; Diamond 1987), however most forest flocks are relatively small (Table 1). Studies comparing flocks in various habitats and in different seasons indicate that more species join flocks when resources are scarce or dispersed (Morse 1970; Croxall 1976; Gram 1998; Maldonado-Coelho \& Marini 2003); mixed-species foraging flocks are typical in winter in high latitude wooded habitats, and usually in the dry season in the tropics (Morse 1970; Croxall 1976; Earlé 1983; Poulsen 1996; Develey \& Peres 2000). Larger numbers of species participate in the flocks observed in late summer and autumn in high latitudes, principally as the result of the addition of a diversity of migrant species (Morse 1970; Rodewald \& Brittingham 2002; Hobson \& van Wilgenburg 2006). Experimental evidence supports the proposal that resource distribution is important in shaping flocking behaviour (Berner \& Grubb 1985; Kubota \& Nakamura 2000). 
Table 1. Mean number of individuals and participating species in various mixed-species flocks in forests

\begin{tabular}{|c|c|c|c|c|}
\hline $\begin{array}{c}\text { Location of study } \\
\text { (number of flocks observed) }\end{array}$ & $\begin{array}{l}\text { Mean number } \\
\text { of individuals }\end{array}$ & $\begin{array}{c}\text { Mean number } \\
\text { of participating } \\
\text { species }\end{array}$ & $\begin{array}{c}\text { Total number } \\
\text { of participating } \\
\text { species }\end{array}$ & Source \\
\hline Brazil, rainy season (42) & 9.1 & 5.8 & 58 & Maldonado-Coelho \& Marini 2003 \\
\hline Brazil, dry season (50) & 10.9 & 6.0 & 71 & Maldonado-Coelho \& Marini 2003 \\
\hline Mexico, tropical deciduous forest (23) & 10.6 & 6.5 & 27 & Gram 1998 \\
\hline Mexico, dry pine/oak forest (42) & 25.9 & 9.9 & 38 & Gram 1998 \\
\hline Mexico, cloud forest (24) & 19.3 & 9.3 & 39 & Gram 1998 \\
\hline Hispaniola (180) & 11.3 & 7.1 & 46 & Latta \& Wunderle 1996 \\
\hline Indonesia (20) & 18.6 & 11.3 & 36 & Croxall 1976 \\
\hline Burma (73) & 19.3 & 6.8 & 52 & King \& Rappole 2001 \\
\hline Bolivia, Andes (63) & 5.4 & 2.8 & 10 & Herzog et al. 2002 \\
\hline Bolivia, Andes (40) & 5.7 & 3.5 & - & Moynihan 1962 \\
\hline Ecuador, Andes (89) & 5.4 & 3.4 & - & Moynihan 1962 \\
\hline Columbia, Andes (34) & 5.8 & 3.9 & - & Moynihan 1962 \\
\hline Louisiana (52) & 12.1 & - & 14 & Morse 1970 \\
\hline Maryland, coniferous forest (106) & 12.8 & - & 14 & Morse 1970 \\
\hline Maryland, mixed forest (60) & 17.9 & - & 13 & Morse 1970 \\
\hline Maine, mixed forest, summer (35) & 16.4 & - & 23 & Morse 1970 \\
\hline Saskatchuan, coniferous forest, summer (215) & 41.1 & 6.6 & 67 & Hobson \& van Wilgenburg 2006 \\
\hline Pennsylvania, deciduous forest, autumn (220) & 22.1 & 9.3 & 60 & Rodewald \& Brittingham 2002 \\
\hline
\end{tabular}


The duration and strength of the relationships between species at the centre of flocks varies from transient to long-term stable associations, and has been identified by Munn \& Terborgh (1979) as the basis of ranking flocks on a continuum. They suggest seabirds, forming casual feeding associations, should sit at one end of the continuum, and at the other end lowland Neotropical antbird flocks, which form permanent, life-long associations cooperatively defending a common territory, represent the most advanced form of the phenomenon. But the size and stability of flock membership sometimes varies enormously and numbers of birds participating fluctuate over short time frames (Powell 1979; Terborgh 1990; Thiollay \& Jullien 1998). In the mixed-species flocks of the Neotropics there are frequently no more than one or two individuals of each species (Davis 1946; Alves \& Cavalcanti 1996; Jullien \& Clobert 2000); any increase in flock size is usually the result of more species becoming involved, not more individuals of any one species joining (Greig-Smith 1978a; Powell 1979). In the Andes species assemblages vary markedly across the habitat mosaic shaped by altitude and aspect, with parallel changes in the species composition of mixed-species flocks, and less stability in the interspecific relationships (Moynihan 1962).

In the marine environment seabird flocks have been described as temporary feeding associations (Munn \& Terborgh 1979), however this does not correctly identify the strength of the relationships between some species. There exist simple transient foraging flocks of seabirds, but also mixed-species foraging flocks in which the species at the core of the flocks show strong inter-specific affinities (Murphy 1936; Sealy 1973; Hoffman et al. 1981; Harrison et al. 1991). In the Southern Ocean the tube-nosed seabirds 
(Procellariiformes) occur more often in mixed-species associations than apart from them (Murphy 1936). There exist poorly understood inter-dependencies that reflect differing flight dynamics, diving abilities and sensory capacity. Differences exist between species in their ability to find prey either directly (e.g. olfactory capability across different spatial scales; Nevitt 2000), or indirectly (e.g. observation of other predators; Harrison et al 1991). For example, black-browed albatrosses (Thalassarche melanophrys) are unambiguous leaders in mixed-species flocks feeding on Antarctic krill (Euphausia superba) around South Georgia (Harrison et al. 1991); interactions with a small group of other species suggesting co-evolved species affiliations. In this case the black-browed albatrosses appear to be better able to track the foraging activities of fur seals (Arctocephalus gazella) and macaroni penguins (Eudyptes chrysolophus) which drive krill to the surface. Seabirds have varied adaptive inter-specific relationships with other seabird species, with predatory fish such as tuna, with seals and with cetaceans (Au \& Pitman 1986; Harrison et al. 1991; Pitman \& Ballance 1992). Mixed-species seabird flocks vary in complexity and the spectrum of inter-specific relationships represented has been understated in the literature.

The function of the mixed-species flocks will largely determine the nature of the interaction between participants and the extent to which stable associations are formed. Whereas seabirds are generally not at risk from predators when at sea and the function of mixed-species flocks relates to foraging (Rand 1954; Hoffman et al. 1981), terrestrial birds are highly vulnerable to predators and many species of open habitats in particular form mixed-species flocks. Herons, egrets and waders appear to have a strong affinity for 
one another and coalesce in mixed-species flocks (Nichols 1931; Caldwell 1981). Passerines of open habitat are also vulnerable to predation, and mixed-species flocks of finches and other granivorous birds are commonly observed (Marler 1956; Cody 1971; Rubenstein et al. 1977; Canales-Delgadillo et al. 2008). Members of mixed-species flocks experience a different balance of selective pressures, and the proximity of competitors is likely to shape foraging behaviour. Barnard \& Thompson (1985) explored the consequences of mixed-species associations in a study of lapwings (Vanellus vanellus), golden plovers (Pluvialis apricaria) and black-headed gulls (Larus ridibundus) - an example of a co-evolved inter-specific association.

Mixed-species flocks are seen across taxa and in most environments and not surprisingly there is enormous variation in the inter-specific relationships between participants. Understanding the extent to which mixed-species flocks structure avian communities (Greenberg \& Gradwohl 1986; Powell 1989; Mönkkönen 1996; Willson 2004) requires differentiating highly co-evolved inter-dependent species from diffusely co-evolved species. Many species associations are not treated as mixed-species flocks, such as flocks of ducks in which congeners show clear affinity (Johnsgard 1978). Foraging flocks of waterfowl are not discussed with the same language used in the description of mixed-species foraging flocks, despite the fact there exist predictable foraging associations such as that between gadwalls (Anas strepera) and American coot (Fulica americana) (McKnight \& Hemp 1998). Rand (1954) terms the foraging behaviour common in inter-specific associations of ducks as 'communal pilfering' which he describes as a 'more or less peaceful appropriation of food.' But there are many 
similarities between this and the associations described as mixed-species flocks; in both cases the flocks include scroungers, and the benefits are unequally distributed between participants. However the literature on forest flocks tends to assume a simple model with convergence evident worldwide in which there are strong mutually beneficial interspecific affinities and a high degree of inter-dependence. While mixed-species flocks are present in all temperate and tropical forests and are convincingly important in these avian communities, but not all represent the apogee of the phenomenon.

\section{CHARACTERISING ROLES OF FLOCK PARTICIPANTS}

The degree of inter-dependence of forest birds in mixed-species flocks has been represented in the vocabulary used in describing the different roles of species (Winterbottom 1949; Munn \& Terborgh 1979). From early observations some species were readily identified as 'regulars' in flocks (Davis 1946), or as critical to the formation of the flock or 'primary association formers' (Gannon 1934). 'Nuclear species' and 'core species' are the terms used most consistently to identify the species that have this central role in flocks (Winterbottom 1949; Rand 1954; Hutto 1994; Hino 1998). Hoffman et al. (1981) used the term 'catalyst' instead to identify the seabird species that through their behaviour attracted other species and so initiated mixed-species foraging flocks. In fact there are different types of leader or nuclear species (Moynihan 1962; Goodale \& Kotagama 2005b), and a great many marginal species with varying propensity to participate in flocks (Munn \& Terborgh 1979; King \& Rappole 2001). 
In many flocks more than one nuclear species is present and they may differ in their behaviour; Moynihan (1962) identified 'active or passive' nuclear species - and in many studies a number of species are central to flock formation and maintenance but one acts as a leader and another more of a follower. In the Central American 'blue and green tanager and honeycreeper alliance' described by Moynihan (1962), plain-coloured tanagers (Tangara inornata) are identified as passive nuclear species in that they are joined and followed by individuals of other species, but have little tendency themselves to join and follow other species. Green honeycreepers (Chlorophanes spiza) are identified as active nuclear species, because they both join and follow other species and also attract followers. This distinction is repeated in other mixed-species foraging flocks of tropical forests such as those described in New Guinea (Diamond 1987) and Madagascar (Hino 1998). The different types of nuclear species may relate to their different roles in flocks, some intra-specifically gregarious leaders (Hutto 1994; Sridhar et al. 2009), while others are not particularly gregarious but good sentinels (Goodale \& Kotagama 2005b). There have doubtless been inconsistencies in the use of this vocabulary, a problem discussed by Winterbottom (1949), and a problem exacerbated by the fact that some species vary in their roles in flocks in different parts of their range (Moynihan 1979).

Identifying the role of a given species will depend upon the particular avifauna and the evolved relationships. Many of the definitions used for tropical forests are inappropriate for characterising birds active in mixed-species flocks of temperate forests (Farley et al. 2008), and vice versa (Stutchbury \& Morton 2001). Hence, definitions are 
often specific to an avian community, or even a given study site. For example, Gram (1998) working in Mexico, identified nuclear species as 'a species that was intraspecifically gregarious (mean number per flock > 3 individuals; Winterbottom 1943, Greig-Smith 1978a), was a regular flock participant (present in more than 50\% of flocks; McClure 1967), was followed more than it followed others (Munn \& Terborgh 1979), displayed a conspicuous plumage or behaviour (Chipley 1977), and remained with the flock continuously.' This array of characteristics is common to many nuclear species in passerine flocks (Hutto 1994; Goodale \& Kotagama 2005a).

Various other types of flock members have been described: 'circumference species' (Winterbottom 1949; Powell 1985), 'peripheral species' (Sullivan 1985; Hoffman et al. 1981), ‘joining species' (Munn 1985), 'occasional species' (Munn \& Terborgh 1979; Farley et al. 2008), 'attendant species' (Rand 1954; Moynihan 1962; Powell 1985; Maldonado-Coelho \& Marini 2003) ‘satellite species' (Dolby \& Grubb 1998; Goodale \& Kotagama 2005b) and 'accidental species' (Davis 1946; Winterbottom 1949; Jullien \& Clobert 2000; Farley et al. 2008). Munn \& Terborgh (1979) identified different types of 'joining species' in their study of lowland Neotropical flocks, for example territorial birds that joined flocks as they passed through their territory, or species from canopy flocks that occasionally switched to understory flocks. Other participants move in and out of flocks, sometimes over short time frames, with varying propensity to participate depending on season, time of day, climate and the species composition of the flock (Powell 1979). Hutto (1994) found that the probability of observing attendant species in mixed-species flocks of small insectivores in Mexico was predicted by their relative 
abundance in the avian community. The birds at the periphery of mixed-species flocks range from species that are inter-specifically gregarious and usually in flocks, to a great many more opportunists. Thus there exists a spectrum of followers in mixed-species associations from highly co-evolved species dependent upon flocks to diffusely coevolved attendants.

The loss of the nuclear species changes the propensity for other species to coalesce into flocks. Diamond (1987) documented the geographic variation over the archipelago of islands around Papua New Guinea, and found that flocks were often altogether absent from particular islands - those without the nuclear species acting as catalysts to flock formation. Maldonado-Coelho \& Marini (2003) found that the loss of the nuclear species Habia rubica in fragmented habitat in coastal Brazil resulted in the absence of lowland mixed-species flocks, despite the presence of most of the other species typical of the flocks. In these examples, the social cohesion of birds associated in mixed-species flocks depended on the activity of one or a few members of diverse avian communities. The opportunity to join mixed-species flocks appears to be important for a diversity of species; local extinction of catalyst or nuclear species may have a disproportionate impact and has been identified as a potentially important conservation issue in both marine and terrestrial ecosystems (e.g. Hoffman et al. 1981; Goodale and Kotagama 2005b).

\section{PREDATOR AVOIDANCE OR FEEDING EFFICIENCY?}

There is no doubt that a bird may be less vulnerable to predators as the result of participating in a mixed-species flock. The birds benefit from 'safety in numbers', and 
also from the 'many eyes effect' - the vigilance and alarm calls of other flock participants (Hamilton 1971; Pulliam 1973; Elgar 1989; Terborgh 1990; Roberts 1996; Beauchamp 2003). The potential advantage for a species in forming inter-specific groups rather than flocking with conspecifics may be in the association with other species that have greater sensory acuity, use a different microhabitat or otherwise behave in such a way that they are more likely to detect predators. The most cited potential foraging benefit of participation in mixed-species flocks is the increased foraging efficiency as the result of shared vigilance (Wiley 1980; Powell 1985; Metcalfe 1989; Roberts 1996; Sasvári \& Hegyi 1998; Thiollay 1999; Herzog et al. 2002; Sridhar et al 2009). However, foraging benefits and predator evasion are impossible to regard independently (Morse 1978; Hutto 1994), and it is perhaps unnecessary to do so. In examining the present functional significance of social foraging, security and energetic benefits are not mutually exclusive (Giraldeau \& Caraco 2000).

The balance of costs and benefits will vary enormously for species with differing feeding behaviours; there exist foraging strategies, for instance bark gleaning or exploration of epiphytes that may make birds particularly vulnerable. Diamond (1987) observed that birds-of-paradise are not able to watch for predators while probing epiphytes, and this 'close focus' feeding behaviour makes them particularly vulnerable. The benefits of associating in a mixed-species flock would be more than that expected by the dilution effect, because species differ in their sensory capacity to detect predators early. Some species have clear functional roles as sentinels (Powell 1985; Munn 1986; Jullien \& Thiollay 1998). A recurrent pattern is the association of a diversity of small birds with vigilant flock members, notably sallying species such as drongos (Dicrurus) 
and flycatchers (Terborgh 1990; Goodale \& Kotagama 2005a). An alternative is in the association with a numerous vocal species; an abundance of companions helps ensure the detection of danger (Goodale \& Kotagama 2005a). There is evidence that woodpeckers and nuthatches seek out parid species as an anti-predator strategy (Sullivan 1985; Dolby \& Grubb 1998, 2000). In an experiment involving playback of chickadee vocalisations, Sullivan (1985) found that downy woodpeckers (Picoides pubescens) reduced their level of vigilance when they could hear chickadee calls, a repeated indication of the presence of their vigilant flock mates.

Some members of flocks benefit less than others because of the social dynamics within the flock; studies of European parid flocks have demonstrated a cost of subordination, in which young and other subordinate birds in flocks are forced to move to peripheral perches where they become more vulnerable to predation (Ekman \& Askemno 1984; Ekman 1987; Suhonen 1993; Suhonen et al. 1993; Krams 1996; Krams 1998). However even though juvenile flock members are sometimes at greater risk from predators than adults, and spend more time in vigilance both against predators and aggressive con-specifics (Carrascal \& Moreno 1992), given their inexperience they still are likely to benefit as the result of feeding with adults, which lead them to good foraging sites (Hogstad 1989).

There are a number of proposals for how birds in mixed-species flocks may find food more effectively (Ward \& Zahavi 1973; Morse 1978; Galef \& Giraldeau 2001). Individuals of different species may benefit from each other through social learning or response facilitation (social facilitation) (Byrne 1994). Area copying and social 
facilitation have been demonstrated experimentally (Krebs 1973; Sasvári \& Hegyi 1998). The success or failure of a bird in a given patch represents public information (Giraldeau \& Caraco 2000) and birds seek out sites where flock mates have been successful - e.g. a new branch or tree (Waite \& Grubb 1988). Greig-Smith (1978b) found Seychelles sunbirds (Nectarinia dussumiera) foraged more effectively when they followed Seychelles white-eyes (Zosterops modesta). When the sunbirds shadowed the foraging white-eyes they concentrated their activity in trees richer in their insect prey. The whiteeyes appeared to be inherently better equipped to sample the environment and evaluate the relative profitability of patches. In a complex landscape, birds may benefit from the community memory, different members of the flock having had experience in finding food in the past lead the others to profitable patches (Giraldeau \& Caraco 2000). If birds learn how to locate more types of food, or learn how to solve foraging problems as the result of associating with other species, they gain access to otherwise unavailable food. Some individuals have more need than others for information on where food can be found, for example migrant birds joining mixed-species flocks at migratory stopovers.

Birds also benefit if they form associations with other species differing in their sensory acuity or modes of locomotion, such that food is detected that would otherwise be missed. For instance, seabirds associate with marine mammals that locate prey using echolocation (e.g. Pitman \& Ballance 1992). Surface-feeding seabirds form mixedspecies flocks in association with penguins, auks or other diving vertebrates such as cetaceans that locate food and also make it available at the surface (Murphy 1936; 
Hoffman et al. 1981; Obst \& Hunt 1990; Harrison et al. 1991; Grebmeier \& Harrison 1992).

The 'gang theory' has been proposed as an important advantage to participants in inter-specific associations (Diamond 1987). There is a greater opportunity for overwhelming territorial defences by associating with other species (Dunbar 1988), and the benefit of associating with a 'gang' may explain the occasional benefit gained by some opportunistic flock participants - territorial birds which become carried along by a flock beyond their own territory boundary. For instance, Moynihan (1962) noted that yellow-thighed finches (Pselliophorus tobialis) would follow mixed-species flocks into the territories of their neighbours.

One way in which mixed-species flocks facilitate foraging is the 'beater effect', in which birds benefit from insects flushed by other flock participants (Munn \& Terborgh 1979; Powell 1985; Diamond 1987; Rodrigues et al. 1994; Hino 1998). While positive interaction is typical within mixed-species flocks of passerines, kleptoparasites are evident, either pilfering food items from flock mates, or dominating patches located by a flock-mate. Behavioural observations suggest that the relationship of species in these flocks may be long-standing and stable, and the costs may be balanced by benefits accrued from their presence - notably alarm calls. Munn (1986) observed species acting as sentinels in mixed-species flocks, Lanio versicolor and Thamnomanes schistogynus, making false warning calls, and so taking the attention of flock mates off intended prey that they then claimed. Kleptoparasitism in many instances in social foraging groups does 
not appear to be aggressive but instead tolerated theft (Giraldeau \& Caraco 2000; King \& Rappole 2001). Indeed aggression between species active in mixed-species flocks is extremely rare and may be evident between conspecifics but not between species, even when neighbouring flocks of passerines meet (Buskirk et al. 1972).

Thus there are benefits of inter-specific associations in environments where there is spatial and temporal unpredictability of food, particularly where birds are vulnerable to predators, and this is the likely starting point for the evolution of mixed-species flocks. But many participants in mixed-species flocks appear to be subject to strong selection for co-existence, with wider consequences to their ecology and behaviour. Weighing up the costs and benefits of participation in terms of feeding benefits and security does not account for the new level of complexity created by the social environment of the flock. The cost of competition must have had some historical role in shaping flock composition and behaviour: which species associate, from which feeding guilds, and how far apart do they feed? For many followers and joiners such a balance may still be important in determining the pattern of participation. But presently some of the species persistent in mixed-species flocks may be beyond the point of no return; they have a suite of adaptations for existing within a flock such that the benefits of living in the flock far outweigh the costs.

\section{NICHE CONSTRUCTION}

As a consequence of the decision to join a mixed-species flock, birds are exposed to different selective pressures than if they remained solitary or among con-specifics. The 
decision to participate in a mixed-species flock transforms the selective regime.

Moreover the species at the centre of mixed-species associations display adaptations that result from generations of close affiliation with one or more species. The evolution of adaptations seen in these highly specialised species can only be understood in the context of the flocks themselves, and represents a conspicuous example of niche construction by relocation as defined by Odling-Smee et al (2003); through their choices (the decision to instigate and maintain flocks) they are modifying their own niche and that of other flock participants. The most persistent members of flocks are species in highly co-evolved species pairs or groupings, and their adaptations go far beyond a general affinity for interspecific association. Powell (1985) describes mixed-species flocks as "groupings whose cohesion is dependent on members' responses to one another, i.e. the flock generates its own raison d'etre."

Eco-evolutionary feedback may have an important role in the evolution of adaptations in flock participants with flock characteristics, notably species composition and behaviour of nuclear species, affecting selection. Eco-evolutionary feedbacks result when populations fundamentally alter their environment through niche construction, and such changes affect the subsequent evolution of the population (Post \& Palkovacs 2009). Nuclear species are creating and maintaining new niche space in a complex environment (Powell 1989; Cody 2000), and their niche constructing activities will affect their fitness, and that of subsequent generations exposed to an avian community characterised by mixed-species flocks. Some mixed-species foraging flocks physically alter the resource distribution (e.g. seabirds), arguably an example of niche construction by perturbation 
(Odling-Smee et al. 2003), some members of flocks actively and predictably making food available that would otherwise not be within reach, with consequences for their own species and others.

Niche construction may weaken selection on some traits while strengthening selection on others, and can lead to new and unexpected evolutionary trajectories (Laland et al. 1999). Adaptations that result from niche construction are described as recipient traits (Odling-Smee et al 2003); the evolution of recipient traits depends upon the frequency of the niche-constructing trait (in this case associating in a mixed-species flock) over generations (Laland \& Sterelny 2006). The tools now available for phylogenetic analysis provide an opportunity to test if adaptations are emerging among taxa as a consequence of their association in mixed-species flocks (Odling-Smee et al. 2003). Mixed-species flocks appear superficially to be the outcome of opportunistic responses of the participants, but this is not necessarily so; the demonstration of recipient traits implies specialisation for a niche defined by a flock and may suggest a degree of inflexibility in the behavioural options open to a bird.

The observed plumages and other signals for inter-specific communication (Moynihan 1962; Wiley 1980; Vuilleumier 1967) may be recipient traits, evidence of niche construction. Highly co-evolved plumages in the nuclear species of Neotropical flocks appear to represent extreme adaptations for inter-specific communication. Brilliant blue and yellow 'themed' plumages characterise tanager-honeycreeper flocks in the high Andes; black and yellow markings characterise montane bush finch flocks in the 
highlands of Chiriqui, in Panama (Moynihan 1968). Moynihan (1968) observed that unrelated species appeared to have evolved convergent plumage (social mimicry) as an adaptation for ensuring positive interactions within flocks, perhaps the mechanism for avoiding aggression. These plumages appear to be the result of strong selection for close inter-specific associations in which visual signals permit birds to control their social environment and their ecological niche. These specialised birds have a fundamental niche defined by their inter-specific association, with both a genetic inheritance (plumage and associated behaviour) and an ecological inheritance. This ecological inheritance in the avian community, composed of species with a high propensity to flock, influenced by the behaviour of their ancestors - affects their opportunities and vulnerabilities.

Of the array of adaptations in birds participating in mixed-species flocks, which are recipient traits? Given the strength of predation as a selective force, niche construction may seem unnecessary to explain why birds associate in flocks. Diffuse co-evolution appears to shape characteristics of plumage and vocalisations in the majority of species and facilitate association in mixed-species flocks. In New Guinea, Diamond (1987) described 'brown and black flocks', made up of a variety of birds in drab brown or black plumage including relatively large species such as drongos, rufous babblers (Pitohui), and a number of immature and female birds-of-paradise (Paradisaeidae). Diamond (1987) suggested that the plumage and many other traits of young birds-of-paradise have been shaped by selection for participation in these flocks. The behaviour of capable individuals can change the foraging opportunities for the less experienced or less able individual such that it has a greater chance of success, or a greater chance of avoiding harm. Neutral 
plumages already exist in many species to diffuse aggression with conspecifics; such birds may be pre-adapted for joining mixed-species flocks. However some species of brightly coloured Tangara species retain dull juvenile plumage longer than normal (e.g. 3 years) and Moynihan (1962) suggested that the neutral plumage of young tanagers may change their inter-specific relationships and permit entry into mixed-species flocks. The dull plumage of young birds although functioning to diffuse aggression is not necessarily the product of niche construction - but extended juvenile plumages may be.

Mixed-species foraging flocks bring competing species into close proximity, and there is the potential for such species associations to generate selection for character displacement, and divergence of adaptations for specific microhabitats or specialised diets. Many investigators have observed that when birds associate in mixed-species flocks they diverge in micro-habitat use or foraging behaviour (Moynihan 1962; Morse 1978; Wiley 1980; Powell 1985; Hutto 1987; Julien \& Clobert 2000; King \& Rappole 2001; Hart \& Freed 2003; Gordon \& Harrison 2010). Potentially the foraging specializations and foraging strategies of some species represent recipient traits, for example specialisations for bark gleaning. Birds of mixed-species flocks seem to include the text book examples of segregation of resources through competitive exclusionwhether seabirds or arboreal passerines (Ashmole 1968; Krebs 2009).

Nuclear species and obligate participants in mixed-species flocks have a variety of characteristics that may be recipient traits. In lowland Neotropical forests they are highly co-evolved with individuals of different species spending their entire lives together, 
defending a common territory (Gradwohl \& Greenberg 1980; Munn 1985; Greenberg \& Gradwohl 1986). The obligate members of these flocks have been shown to have better survival when compared to facultative participants and to birds that do not participate in flocks (Jullien \& Clobert 2000). They have an array of adaptations for maintaining social cohesion during breeding, including tolerance of egg neglect, lower chick feeding rates, and early nest departure of chicks so that they can accompany adults in flocks (Jullien \& Clobert 2000).

The species groups typically found to be active in mixed-species flocks of the species-rich tropical forests are often themselves species-rich. Large genera in the Neotropics include Tangara, the tanagers that are nuclear species in canopy flocks, and Myrmotherula, ant wrens, nuclear species in understory flocks of lowland forests (Munn \& Terborgh 1979; Munn 1985). Tropical bird communities are species-rich in part as the result of myriad biotic selective pressures (Stutchbury \& Morton 2001). Nuclear species in the mixed-species flocks of tropical forests are creating and maintaining opportunities for other species in the avian community. Niche construction can lead to co-evolutionary episodes, greater specialisation, and potentially have implications for the evolution of biological diversity (Crespi 2004; Laland and Boogert 2008; Duckworth 2009; Post \& Palkovacs 2009).

\section{CONCLUSION}

Niche construction may not be necessary to explain all adaptations for participation in flocks given the strength of predation and energy acquisition in shaping animal 
adaptation. The convergent patterns of behaviour in a large number of unrelated species suggests commonality in the selective pressure, and it has been argued that the improved security in mixed-species flocks is sufficient to understand the ubiquity of flocks and the behaviour of participants (Buskirk 1976; Thiollay 1999). However this is not sufficient to explain the array of adaptations observed among many species active in flocks. We propose that nuclear species, the bird species central to the formation and maintenance of mixed-species foraging flocks, can be described as niche constructors as evidenced by traits such as plumages and vocalisations that act as signals facilitating flock cohesion. Such obligate participants in their lifetimes will succeed or fail differentially both because of the genetic legacy, the set of adaptations they inherit, and the ecological legacy in the form of the relative abundance and composition of the flock membership.

The extensive literature on mixed-species flocks of birds, and the growing theoretical understanding of the relevant evolutionary mechanisms (Holt \& Gaines 1992; Stamps 2003; Lehmann 2007; Duckworth 2009) make this a good time for further investigation of niche construction by relocation. The vocabulary describing the roles of participants in flocks provides clues as to the species likely to be niche constructors. The focus of future research should be on recipient traits, not only plumages and vocalisations but also the selection for microhabitat, foraging strategy, egg neglect, breeding behaviour and the dispersal of young. Comparative analyses that control for phylogenetic signal permit comparisons of such traits across groups of birds - those with a high propensity to join mixed-species flocks with those that join flocks with conspecifics or are solitary (Harvey \& Pagel 1991; Odling-Smee et al. 2003). Study would also be valuable of the behavioural 
variation evident in populations across their ranges, in the propensity to join flocks, affinities for other species, or in the roles played within mixed-species flocks (Moynihan 1979; Wiley 1980; Pomara et al. 2003). More information on the evolution of mixedspecies flocking behaviour may exist in this variation than in the examples of convergence. Mixed-species groups of other organisms (mammals such as primates and cetaceans; fish of tropical reefs or cichlids) similarly may lead to eco-evolutionary feedback, one or more species having profound effects on the selective regime of other associated species and changing subsequent evolution (Yakaoka 1991; Pitcher \& Parrish 1996; Stensland et al. 2003). The new literature on niche construction points to the importance of understanding the interdependencies of species in the interest of conservation (Laland \& Boogert 2008). Some species rely on others to access resources, with knock on effects for their very survival - their conservation dependent on the complex dynamics within mixed-species groups.

Finally, we hypothesise that the additional niche dimension represented by mixedspecies flocks may be contributing to an adaptive radiation in tropical forest communities, and merits further investigation. The importance of the social environment in tropical avian communities and the consequences of such behavioural decisions may ultimately result in accelerated rates of evolutionary change (Odling-Smee et al. 2003). A very large number of bird species are active in mixed-species flocks, whether as facultative participants or as nuclear in their formation and maintenance, with consequences for avian communities. 


\section{Acknowledgements}

We thank Anglia Ruskin University for awarding a research sabbatical which permitted completion of this work, and two anonymous reviewers for their insights and suggestions.

\section{References}

Alves, M. A. S. \& Cavalcanti, R. B. 1996. Sentinel behavior, seasonality and the structure of bird flocks in a Brazilian savanna. Ornitologia Neotropical, 7, 43-51.

Ashmole, N.P. 1968. Body size, prey size, and ecological segregation in five sympatric tropical terns (Aves:Laridae). Systematic Zoology, 17, 292-304.

Au, D. W. K. \& Pitman, R. L. 1986. Seabird interactions with tuna and dolphins in the eastern tropical Pacific. Condor, 88, 304-317.

Barnard, C. J. \& Thompson, D. B. A. 1985. Gulls and Plovers. The Ecology and Behaviour of Mixed-species Feeding Groups. New York: Columbia University Press.

Bates, H. W. 1863. The Naturalist on the River Amazons. London: John Murray.

Beauchamp, G. 2003. Group-size effects on vigilance: a search for mechanisms.

Behavioral Processes, 63, 111-121. 
Bell, H. L. 1982. A bird community of lowland rainforest in New Guinea. 5. Mixedspecies feeding flocks. Emu, 82, 256-275.

Berner, T. O. \& Grubb, Jr. T. C. 1985. An experimental analysis of mixed-species flocking in birds of a deciduous woodland. Ecology, 66, 1229-1236.

Buskirk, W. H. 1976. Social systems in a tropical forest avifauna. American Naturalist, 110, 293-310.

Buskirk, W. H., Powell, G. V. N., Wittenberger, J. F., Buskirk, R. E. \& Powell, T. U. 1972. Interspecific bird flocks in tropical highland Panama. Auk, 89, 612-624.

Byrne, R.W. 1994. The evolution of intelligence. In: Behaviour and Evolution (Ed. by P.J.B Slater \& T.R. Halliday), Cambridge, UK: Cambridge University Press.

Caldwell, G. S. 1981. Attraction to tropical mixed-species heron flocks: proximate mechanism and consequences. Behavioral Ecology and Sociobiology, 8, 99-103.

Canales-Delgadillo, J. C., Scott-Morales, L. M., Correa, M. C. \& Moreno, M. P. 2008. Observations on flocking behavior of Worthen's Sparrows and occurrence in mixed-species flocks. Wilson Journal of Ornithology, 120, 569-574. 
Carrascal, L. M. \& Moreno, E. 1992. Proximal costs and benefits of heterospecific social foraging in the great tit, Parus major. Canadian Journal of Zoology, 70, $1947-$ 1952.

Chipley, R. M. 1977. The impact of wintering migrant wood warblers on resident insectivorous passerines on subtropical Colombian oak woods. Living Bird, 15, 119-141.

Cody, M.L. 1971. Finch flocks in the Mohave Desert. Theoretical Population Biology, 2, 141-158.

Cody, M.L. 1985. Habitat Selection in Birds. Orlando, Florida: Academic Press.

Cody, M. L. 2000. Antbird guilds in the lowland Caribbean rainforest of southeastern Nicaragua. Condor, 102, 784-794.

Crespi, B.J. 2004. Vicious circles: positive feedback in major evolutionary and ecological transitions. Trends in Ecology and Evolution, 19, 627-633.

Croxall, J. P. 1976. The composition and behaviour of some mixed-species bird flocks in Sarawak. Ibis, 118, 333-346.

Davis, D. E. 1946. A seasonal analysis of mixed flocks of birds in Brazil. Ecology, 27, 168-181. 
Develey, P. F. \& Peres, C.A. 2000. Resource seasonality and the structure of mixed species bird flocks in a coastal Atlantic forest of southeastern Brazil. Journal of Tropical Ecology, 16, 33-53.

Diamond, J. 1987. Flocks of brown and black New Guinean birds: a bicoloured mixedspecies foraging association. Еmu, 87, 201-211.

Dolby, A. S. \& Grubb, Jr. T. C. 1998. Benefits to satellite members in mixed-species foraging groups: an experimental analysis. Animal Behaviour, 56, 501-509.

Dolby, A. S. \& Grubb, Jr. T. C. 2000. Social context affects risk taking by a satellite species in a mixed-species foraging group. Behavioural Ecology, 11, 110-114.

Duckworth, R.A. 2009. The role of behavior in evolution: a search for a mechanism. Evolutionary Ecology, 23, 513-531.

Dunbar, R. I. M. 1988. The evolutionary implications of social behaviour. In: The Role of Behavior in Evolution (Ed. by H.C. Plotkin), Cambridge, Mass: MIT Press.

Earlé, R. A. 1983. Notes on bird parties in some Transvaal indigenous forests. Ostrich, 54, 176-178. 
Ekman, J. B. 1987. Exposure and time use in willow tit flocks: the cost of subordination. Animal Behaviour, 35, 445-452.

Ekman, J. B. \& Askenmo, C. E. H. 1984. Social rank and habitat use in willow tit groups. Animal Behaviour, 32, 508-514.

Elgar, M. A. 1989. Predator vigilance and group size in mammals and birds: a critical review of the empirical evidence. Biological Review, 64, 13-33.

Farley, E. A., Sieving, K. E. \& Contreras, T. A. 2008. Characterizing complex mixedspecies bird flocks using an objective method for determining species participation. Journal of Ornithology, 149, 451-468.

Galef, B. G. \& Giraldeau, L.-A. 2001. Social influences on foraging in vertebrates: causal mechanisms and adaptive functions. Animal Behaviour, 61, 3-15.

Gannon, G.R. 1934. Associations of small insectivorous birds. Emu, 34, 122-129.

Giraldeau, L.-A., \& Caraco, T. 2000. Social Foraging Theory. Princeton, New Jersey: Princeton University Press.

Goodale, E. \& Kotagama, S. W. 2005a. Alarm calling in Sri Lankan mixed-species bird flocks. Auk, 122, 108-120. 
Goodale, E. \& Kotagama, S.W. 2005b. Testing the roles of species in mixed-species bird flocks of a Sri Lankan rain forest. Journal of Tropical Ecology, 21, 669-676.

Gordon, A.E.V. \& Harrison, N.M. 2010. Observations of mixed-species bird flocks at Kichwa Tembo Camp, Kenya. Ostrich, 81, 259-264.

Gradwohl, J. \& Greenberg, R. 1980. The formation of antwren flocks of Barro Colorado Island, Panama. Auk, 97, 385-395.

Gram, W. K. 1998. Winter participation by Neotropical migrant and resident birds in mixed-species flocks in northeastern Mexico. Condor, 100, 44-53.

Grebmeier, J. M. \& Harrison, N. M. 1992. Seabird feeding on benthic amphipods facilitated by gray whale activity in the northern Bering Sea. Marine Ecology-Progress Series, 80, 125-133.

Greenberg, R. \& Gradwohl, J. 1986. Constant density and stable territoriality in some tropical insectivorous birds. Oecologia, 69, 618-625.

Greig-Smith, P. W. 1978a. The formation, structure and function of mixed-species insectivorous bird flocks in West African Savanna Woodland. Ibis, 120, 284-297. 
Greig-Smith, P. W. 1978b. Imitative foraging in mixed-species flocks of Seychelles birds. Ibis, 120, 233-235.

Hamilton, W. D. 1971. Geometry of the selfish herd. Journal of Theoretical Biology, 31, 295-311.

Harrison, N. M., Whitehouse, M. J., Heinemann, D., Prince, P. A., Hunt G. L. Jr. \& Veit, R. R. 1991. Observations of multi-species seabird flocks around South Georgia. Auk, 108, 801-810.

Hart, P.J. \& Freed, L.A. 2003. Structure and dynamics of mixed-species flocks in a Hawaiian rain forest. $A u k, \mathbf{1 2 0}, 82-95$.

Herzog, S. K., Soria, R., Troncoso, A. \& Matthysen, E. 2002. Composition and structure of avian mixed-species flocks in a high-Andean Polylepis forest in Bolivia. Ecotropica, 8, 133-143.

Hino, T. 1998. Mutualistic and commensal organization of avian mixed-species foraging flocks in a forest of western Madagascar. Journal of Avian Biology, 29, 17-24.

Hobson, K. A. \& van Wilgenburg, S. 2006. Composition and timing of post-breeding multi-species feeding flocks of boreal forest passerines in Western Canada. Wilson Journal of Ornithology, 118, 164-172. 
Hoffman, W., Heinemann, D. \& Wiens, J. A. 1981. The ecology of seabird feeding flocks in Alaska. Auk, 98, 437-456.

Hogstad, O. 1989. Subordination in mixed-age bird flocks - a removal study. Ibis, 131, 128-134.

Holt, R. D. \& Gaines, M. S. 1992. Analysis of adaptation in heterogeneous landscapes: implications for the evolution of fundamental niches. Evolutionary Ecology 6, 433-447.

Hunt, G. L., Jr., Harrison, N. M., Hamner, W. M. \& Obst, B. S. 1988. Observations of a mixed-species flock of birds foraging on euphausiids near St. Matthew Island, Bering Sea. $A u k, \mathbf{1 0 5}, 345-349$.

Hutto, R. L. 1987. A description of mixed-species insectivorous bird flocks in western Mexico. Condor, 89, 282-292.

Hutto, R. L. 1994. The composition and social organization of mixed-species flocks in a tropical deciduous forest in western Mexico. Condor, 96, 105-118.

Johnsgard, P. A. 1978. Ducks, Geese, and Swans of the World. Lincoln, Nebraska: University of Nebraska Press. 
Jullien, M. \& Clobert, J. 2000. The survival value of flocking in Neotropical birds: reality or fiction? Ecology, 81, 3416-3430.

Jullien, M. \& Thiollay, T. M. 1998. Multi-species territoriality and dynamics of Neotropical forest understory bird flocks. Journal of Animal Ecology, 67, 227-252.

King, D. I. \& Rappole, J. H. 2001. Mixed-species bird flocks in dipterocarp forest of north-central Burma (Myanmar). Ibis, 143, 380-390.

Krakauer, D. C., Page, K. M. \& Erwin, D. H. 2009. Diversity, dilemmas, and monopolies of niche construction. American Naturalist, 173, 26-40.

Krams, I. 1996. Predation risk and shifts of foraging sites in mixed Willow and Crested tit flocks. Journal of Avian Biology, 27, 153-156.

Krams, I. 1998. Rank dependent fattening strategies of Willow tit Parus montanus and Crested tit Parus cristatus mixed flock members. Ornis Fenn, 75, 19-26.

Krebs, C.J. 2009. Ecology. Harlow, UK: Pearson Education.

Krebs, J. R. 1973. Social learning and the significance of mixed-species flocks of chickadees (Parus spp.). Canadian Journal of Zoology, 51, 1275-1278. 
Kubota, H. \& Nakamura M. 2000. Effects of supplemental food on intra- and interspecific behaviour of the Varied tit (Parus varius). Ibis, 142, 312-319.

Laland, K. N. \& Boogert, N. J. 2008. Niche construction, co-evolution and biodiversity. Ecological Economics, 69, 731-736.

Laland, K.N., Odling-Smee, J. \& Feldman, M.W. 2004. Niche construction: do the changes that organisms make to their habitats transform evolution and influence natural selection? Nature, 429, 609.

Laland, K.N., Odling-Smee, J. \& Feldman, M.W. 1999. Evolutionary consequences of niche construction and their implications for ecology. Proceedings of the National Academy of Science U.S.A., 96, 10242-10247.

Laland, K.N. \& Sterelny, K. 2006. Seven reasons (not) to neglect niche construction. Evolution, 60, 1751-1762.

Latta, S. C. \& Wunderle, Jr., J.M. 1996. The composition and foraging ecology of mixed-species flocks in pine forests of Hispaniola. Condor, 98, 595-607.

Lehmann, L. 2007. The adaptive dynamics of niche constructing traits in spatially subdivided populations: evolving posthumous extended phenotypes. Evolution, 62, 549566. 
Maldonado-Coelho, M. \& Marini, M. A. 2003. Mixed-species bird flocks from Brazilian Atlantic forest: the effects of forest fragmentation and seasonality on their size, richness and stability. Biological Conservation, 116, 19-26.

Marler, P. 1956. Behaviour of the Chaffinch Fringilla coelebs. Behaviour. Supplement, $5,1-184$.

McClure, H. E. 1967. The composition of mixed species flocks in lowland and submontane forests of Malaya. Wilson Bulletin, 79, 131-154.

McKnight, S. \& Hepp, G. R. 1998. Foraging-niche dynamics of gadwalls and American coots in winter. $A u k, \mathbf{1 1 5}, 670-683$.

Metcalfe, N. B. 1989. Flocking preferences in relation to vigilance benefits and aggression costs in mixed-species shorebird flocks. Oikos, 56, 91-98.

Mönkkönen, M., Forsman, J.T. \& Helle, P. 1996. Mixed-species foraging aggregations and heterospecific attraction in boreal bird communities. Oikos, 77, 127-136.

Morse, D. H. 1970. Ecological aspects of some mixed-species foraging flocks of birds. Ecological Monographs, 40, 119-168. 
Morse, D. H. 1978. Structure and foraging patterns of flocks of tits and associated species in an English woodland during the winter. Ibis, 120, 295-312.

Moynihan, M. 1962. The organization and probable evolution of some mixed-species flocks of Neotropical Birds. Smithsonian Miscellaneous Collections, 143, 1-140.

Moynihan, M. 1968. Social mimicry; character convergence versus character displacement. Evolution, 22, 315-331.

Moynihan, M. 1979. Geographic variation in Social Behaviour and in Adaptations to Competition among Andean Birds. Publications of the Nuttall Ornithological Club, 18, $1-162$.

Munn, C. A. 1985. Permanent canopy and understory flocks in Amazonia: species composition and population density. Ornithological Monographs, 36, 683-712.

Munn, C. A. 1986. Birds that 'cry wolf'. Nature, 319, 143-145.

Munn, C. A. \& Terborgh, J. W. 1979. Multi-species territoriality in Neotropical foraging flocks. Condor, 81, 338-347.

Murphy, R. C. 1936. Oceanic birds of South America. New York: American Museum of Natural History. 
Nevitt, G.A. 2000. Olfactory foraging by Antarctic procellariiform seabirds: life at high Reynolds numbers. Biological Bulletin 198: 245-253.

Nichols, J. T. 1931. Notes on the flocking of shore birds. Auk, 48, 181-185.

Obst, B. S. \& Hunt G. L. Jr. 1990. Marine birds feed at gray whale mud plumes in the Bering Sea. Auk, 107, 678-688.

Odling-Smee, F. J., Laland, K. N. \& Feldman, M. W. 1996. Niche Construction. American Naturalist, 147, 641-648.

Odling-Smee, F. J., Laland, K. N. \& Feldman, M. W. 2003. Niche Construction. Princeton, New Jersey: Princeton University Press.

Pitcher, T.J. \& Parrish, J.K. 1996. Function of shoaling behaviour in teleosts. In: Behaviour of Teleost Fishes. (Ed. by T.J. Pitcher). Fish and Fisheries Series 7. London: Chapman and Hall.

Pitman, R. L. \& Ballance, L. T. 1992. Parkinson's petrel distribution and foraging ecology in the eastern Pacific: aspects of an exclusive feeding relationship with dolphins. Condor, 94, 825-835. 
Pomara, L. Y., Cooper, R. J. \& Petit, L. J. 2003. Mixed-species flocking and foraging behavior of four Neotropical warblers in Panamanian shade coffee fields and forests. Auk 120, $1000-1012$.

Post, D. M \& Palkovacs, E. P. 2009. Eco-evolutionary feedbacks in community and ecosystem ecology: interactions between the ecological theatre and the evolutionary play. Philosophical Transactions of the Royal Society B, 364, 1629-1640.

Poulsen, B. O. 1996. Relationships between frequency of mixed-species flocks, weather and insect activity in a montane cloud forest in Ecuador. Ibis, 138, 466-470.

Powell, G. V. N. 1979. Structure and dynamics of interspecific flocks in a Neotropical mid-elevation forest. Auk, 96, 375-390.

Powell, G. V. N. 1985. Sociobiology and adaptive significance of interspecific foraging flocks in the Neotropics. Ornithological Monographs, 36, 713-732.

Powell, G. V. N. 1989. On the possible contribution of mixed species flocks to species richness in neotropical avifaunas. Behavioural Ecology and Sociobiology, 24, 387-393.

Pulliam, H. R. 1973. On the advantages of flocking. Journal of Theoretical Biology, 38, 419-422. 
Rand, A. L. 1954. Social feeding behavior of birds. Fieldiana: Zoology, 36, 1-71.

Remsen, J. V. Jr. 1985. Community organization and ecology of birds of high elevation humid forest of the Bolivian Andes. Ornithological Monographs, 36, 683-712.

Roberts, G. 1996. Why individual vigilance declines as group size increases. Animal Behaviour, 51, 1077- 1086.

Rodewald, P.G. \& Brittingham, M. C. 2002. Habitat use and behavior of mixed species landbird flocks during fall migration. Wilson Bulletin of Ornithology, 114, 87-98.

Rodrigues, M., Machado, C. G., Alvares, S. M. R. \& Galetti, M. 1994. Association of the black-goggled tanager (Trichothraupis melanops) with flushers. Biotropica, 26, 472475.

Rubenstein, D. I., Barnett, R. J., Ridgely, R. S \& Klopfer, P. H. 1977. Adaptive advantages of mixed-species feeding flocks among seed-eating finches in Costa Rica. Ibis, 119, 10-29.

Sasvári, L. \& Hegyi, Z. 1998. How mixed-species foraging flocks develop in response to benefits from observational learning. Animal Behaviour, 55, 1461-1469. 
Sealy, S. G. 1973. Interspecific feeding assemblages of marine birds off British Columbia. Auk, 90, 796-802.

Sridhar, H., Beauchamp, G. \& and Shanker, K. 2009. Why do birds participate in mixed-species foraging flocks? A large-scale synthesis. Animal Behaviour, 78, 337-347.

Stensland, E., Angerbjörn, A. \& Berggren, P. 2003. Mixed species groups in mammals. Mammal Review, 33, 205-223.

Stamps, J. 2003. Behavioural processes affecting development: Tinbergen's fourth question comes of age. Animal Behaviour, 66, 1-13.

Stutchbury, B. J. M. \& Morton, E. S. 2001. Behavioral Ecology of Tropical Birds. London: Academic Press.

Suhonen, J. 1993. Predation risk influences the use of foraging sites by tits. Ecology, 74, 1197-1203.

Suhonen, J., Halonen, M \& Mappes, T. 1993. Predation risk and the organization of the Parus guild. Oikos, 66, 94-100.

Sullivan, K. 1985. Selective alarm calling by downy woodpeckers in mixed-species flocks. Auk, 102, 184-187. 
Terborgh, J. 1990. Mixed flocks and polyspecific associations: costs and benefits of mixed groups to birds and monkeys. American Journal of Primatology, 21, 87-100.

Thiollay, J-M. 1999. Frequency of mixed species flocking in tropical forest birds and correlates of predation risk: an intertropical comparison. Journal of Avian Biology, 30, 282-294.

Thiollay, J-M. \& M. Jullien, M. 1998. Flocking behaviour of foraging birds in a Neotropical rain forest and the antipredator defence hypothesis. Ibis, 140, 382-394.

Vuilleumier, F. 1967. Mixed species flocks in Patagonian forests, with remarks on interspecies flock formation. Condor, 69, 400-404.

Waite, T.A. \& Grubb, T.C., Jr. 1988 Copying of foraging locations in mixed-species flocks of temperate deciduous woodland birds: an experimental study. Condor, 90, 132140.

Ward, P. \& Zahavi, A. 1973. The importance of certain assemblages of birds as 'information centres' for food finding. Ibis, 115, 517-534.

Wiens, J. A. 1989. The Ecology of Bird Communities: Volume 2 Processes and Variation. Cambridge, UK: Cambridge University Press. 
Wiley, R. H. 1980. Multi-species antbird societies in lowland forests of Surinam and Ecuador: stable membership and foraging differences. Journal of Zoology, London, 191, $127-145$.

Willson, S. K. 2004. Obligate army-ant-following birds: a study of ecology, spatial movement patterns, and behavior in Amazonian Peru. Ornithological Monographs, 55, $1-67$.

Winterbottom, J. M. 1943. On woodland bird parties in northern Rhodesia. Ibis, 85, $437-442$.

Winterbottom, J. M. 1949. Mixed bird parties in the tropics, with special reference to Northern Rhodesia. Auk, 66, 258-263.

Wright, J. P., Jones, C. G. \& Flecker, A. S. 2002. An ecosystem engineer, the beaver, increases species richness at the landscape scale. Oecologia, 132, 96-101.

Yamaoka, K. 1991. Feeding relationships. In: Cichlid Fishes. Behaviour, Ecology and Evolution. (Ed. by M.H.A. Keenleyside). Fish and Fisheries Series 2. London: Chapman and Hall. 